Contents List available at VOLKSON PRESS

Engineering \& Technology Innovations (ETI)

DOI : http://doi.org/10.26480/iceti.01.2017.101.104

\title{
COMPREHENSIVE EVALUATION MODEL OF ENERGY TRUST PROJECT BASED ON REGIONAL DISTRIBUTION NETWORK
}

\author{
Yong Peng*, Guanrong Pei, Han Zhang, Dan Li \\ State Grid Energy Conservation Service Co.,Ltd.,Beijing 100052, China \\ *pengyongbj@163.com \\ *Corresponding author.E-mail address: wdh1018@hhu.edu.cn
}

\section{ARTICLE DETAILS}

\section{Article History:}

Received 02 october 2017

Accepted 06 october 2017

Available online 11 october 2017

Keywords:

Regional distribution network, Energy trusteeship mod, Comprehensive evaluation

\section{ABSTRACT}

In recent years, as the energy conservation and emissions reduction pressure of power enterprises increasing, the application of the energy performance contracts in the energy-saving and loss-reducing of distribution network were receiving more and more attention. As an important mode of contract energy management, energy trusteeship is a perfect choice for the energy-saving reconstructs the regional distribution network. In order to provide the decisionmaking of the energy trusteeship project of regional distribution network for energy-saving service companies and power enterprises, the paper designed the comprehensive evaluation index system of energy trusteeship model of regional distribution network from the five dimensions of economy, technology, society, environment and security, and then used Analytic Hierarchy Process to calculate the weight of evaluation index. Finally, the comprehensive evaluation model of the energy trusteeship project of regional distribution network was constructed. The model can be used to evaluate the energy trusteeship project of regional distribution network objectively, and provide the scientific basis for the project decision-making.

\section{INTRODUCTION}

The environmental pollution in China was increasing worse in recent years, and the government pay more attention to energy conservation and emissions reduction. In order to promote the development of energy conservation and emissions reduction industry, the energy performance contracts (EPC) was introduced in Energy saving service market and got the support of the Chinese government. EPC is the market model that energy-saving service companies provide a complete set of energy-saving services for Energy-consumption enterprises in the form of contract, and help the energy-consuming units achieve energy-saving target [1]; the EPC has developed rapidly in many developed countries, such as the United States, Canada and Japan [2-5]. The Energy trusteeship is an important kind model of EPC, and has also attracted more and more attention both at home and abroad.

Nowadays, a lot of scholars have researched the EPC application in the field of the power grid energy-saving. For example, Wenxiu Xu proved that the low-carbon optimization model of distribution network on energysaving guarantee and energy-saving benefit sharing can reduce the loss of distribution network and improve power quality and reliability effectively [6]. Huang Na took the South China Power Grid energy-saving services as an example to describe the advantages and difficulties of the energy trusteeship model [7]. Yulin WU took the Guangdong power grid company as an example to systematically analyse the feasibility of the EPC in the aspects of economic and sociality value, policy and technology [8]. Ming Lei analysed the necessity and feasibility of the power Grid Company's EPC, and provided some suggestions for the EPC from the aspects of implementing subject, service area, operation mode and risk management of[9]. Besides, some scholars have studied the evaluation method of energy-saving and loss-reducing of distribution network. For example, Xiaohui HAN constructed the evaluation index system and comprehensive evaluation model of rural low-voltage distribution network energy efficiency [10]; Li Tao used interval method to divide the line loss indicators and establish the evaluation method of different intervals of line losses [11].

According to the existing research results, the paper would construct the comprehensive evaluation model of the energy trusteeship project of regional distribution network in order to evaluate the energy trusteeship project of regional distribution network objectively. The paper is organized as follows: Section 2, design the evaluation index system of the regional distribution network energy trusteeship project and calculate the evaluation index weight; Section 3 , construct the comprehensive evaluation model of the energy trusteeship project of regional distribution network; Section 4, give some conclusions.

\section{The design of evaluation index system}

The comprehensive evaluation index design of the energy trusteeship project of regional distribution network should reflect the influence factor and the project implementation effect scientifically and objectively, and evaluate the comprehensive benefits and feasibility accurately. Therefore, the paper designed the comprehensive evaluation index system from the five dimensions of economy, technicality, sociality, environmentality and security. The twenty-four evaluation indexes were selected in the paper, in order to comprehensively reflect and scientifically evaluate the energy trusteeship project feasibility of the regional distribution network.

\subsection{The economy evaluation index}

The investment of the energy trusteeship project of regional distribution network is high, and during the contract period, the energy-saving service companies need to be in charge of the operation and maintenance of the project and undertake the operation and maintenance cost, causing that the energy-saving service companies have to be faced with larger economic pressure. Therefore, the economic effect estimation is of vital importance for the comprehensive evaluation and investment decisionmaking of the energy trusteeship project of regional distribution network. As regards the economy evaluation $\left(B_{1}\right)$, the paper selected the eight evaluation indexes, including the investment finance cost ( $\left.T F C_{-} C_{11}\right)$, energy-saving transformation cost $\left(E T C_{-} C_{12}\right)$, operating and maintenance cost $\left(O M C_{-} C_{13}\right)$, energy audit cost $\left(E A C_{-} C_{14}\right)$, investment payback period $\left(I P P_{-} C_{15}\right)$, net present value $\left(N P V_{-} C_{16}\right)$, total investment return rate $\left(T R R_{-} C_{17}\right)$ and internal return rate $\left(I R R_{-} C_{18}\right)$, in order to evaluate the economic effectiveness and feasibility systematically. 


\subsection{The technicality evaluation index}

The energy-saving technology has great a significant effect on the conserve energy effect of the energy trusteeship project of regional distribution network, a perfecter technical proposal is contribute to the successful implementation of the project. Therefore, the technical evaluation is an extremely important and key part of the comprehensive evaluation of the regional distribution network energy trusteeship project.

There are the five evaluation indexes, namely technological transformation proposal $\left(T T P_{-} C_{21}\right)$, technical maturity $\left(T M_{-} C_{22}\right)$, technical applicability $\left(T A p_{-} C_{23}\right)$, technology advancement $\left(T A d_{-} C_{24}\right)$ and technical reliability $\left(T R_{-} C_{25}\right)$, were selected with respect to the technicality evaluation $\left(B_{2}\right)$ in the paper, in order to evaluate the technical feasibility accurately.

\subsection{The sociality evaluation index}

The sociality mainly refers to the social environment that the regional distribution system energy trusteeship project is face with, such as policy and economy environment, the social environment has a direct or indirect influence on the implementation effect of energy trusteeship project. So the comprehensive evaluation must contain the social environment assessment in order to ensure comprehension and feasibility of the evaluation.

About the sociality evaluation $\left(B_{3}\right)$, the four sociality evaluation indexes of the policy subsidies intensity $\left(P S I_{-} C_{31}\right)$, tax relief intensity $\left(T R I_{-} C_{32}\right)$, policy stability $\left(P S_{-} C_{33}\right)$ and regional economic growth $\left(R E G_{-} C_{34}\right)$ were designed, so as to evaluate the feasibility from the social perspective.

\subsection{The environmentality evaluation index}

With deterioration of environmental pollution and energy shortage problem, the energy conservation and emissions reduction pressure is increasing. The purpose of diminishing line loss and economizing power energy is to improve energy efficiency and abate the environment pollution. So the comprehensive evaluation should include the environmental benefits assessment.

As regards environmentality evaluation $\left(B_{4}\right)$, the paper chose the three evaluation indexes, including the loss reduction rate $\left(L R R_{-} C_{41}\right)$, energy saving amount ( $E A S_{-} C_{42}$ ) and carbon emission reduction amount ( $C R E_{-} C_{43}$ ), for purpose of reflecting and evaluating the environmental effectiveness and feasibility.

\subsection{The security evaluation index}

The safety and stability of power grid operation is of vital importance for the economic and social development, and the implementation of the energy trusteeship project is based on the premise of ensuring the power grid security. Hence the security evaluation $\left(B_{5}\right)$ is an indispensable part of the comprehensive evaluation of the regional distribution system energy trusteeship project.

There were the four indexes, which were selected to evaluate the feasibility from the perspective of the power distribution network security, in the paper, including the power supply reliability $\left(P S R_{-} C_{51}\right)$, voltage qualified rate $\left(V Q R_{-} C_{52}\right)$, frequency qualified rate $\left(F Q R_{-} C_{53}\right)$ and power load stability $\left(L S_{-} C_{52}\right)$.

\subsection{The comprehensive evaluation index system}

Finally, the comprehensive evaluation index system of the energy trusteeship project of the regional distribution network $\left(N T P_{-} R D N\right)$ was constructed on basis of selecting the twenty-four evaluation indexes from the five dimensions of the economy, technicality, sociality, environmentality and security. The comprehensive evaluation index system was shown in the Fig. 1.

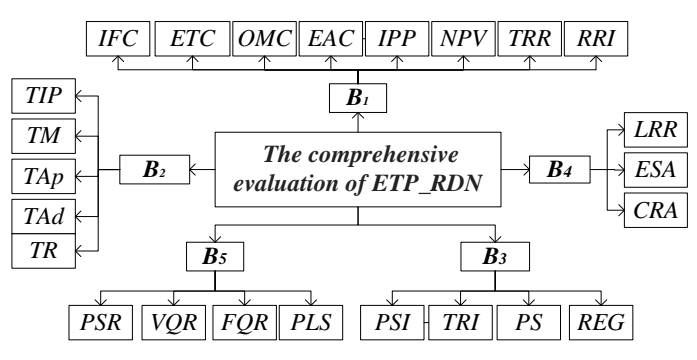

Fig1: Comprehensive evaluation index system of $N T P_{-} R D N$

3. The comprehensive evaluation model construction of the energy trusteeship project of regional distribution system

\subsection{The index weight calculation}

On the basis of designing comprehensive evaluation index system, the experts and scholars, technical personnel and management personnel of the relevant areas to investigate the relative importance of the evaluation indexes in the form of questionnaires, and collected the evaluation data of the comprehensive evaluation index of the regional distribution network energy trusteeship project feasibility. And then the paper sorted out the weight judgment matrix of comprehensive evaluation indexes based on analytic hierarchy process.

The weight judgment matrix $A-B$ of the first-level index of comprehensive evaluation:

$$
A-B=\left|\begin{array}{ccccc}
1 & 3 & 4 & 4 & 2 \\
1 / 3 & 1 & 3 & 3 & 1 / 2 \\
1 / 4 & 1 / 3 & 1 & 1 / 2 & 1 / 4 \\
1 / 4 & 1 / 3 & 2 & 1 & 1 / 3 \\
1 / 2 & 2 & 4 & 3 & 1
\end{array}\right|
$$

The weight judgment matrix $B_{1}-C$ of the second-level index of economy evaluation:

$B_{1}-C=\left|\begin{array}{cccccccc}1 & 2 & 2 & 4 & 2 & 2 & 1 / 2 & 2 \\ 1 / 2 & 1 & 2 & 4 & 2 & 2 & 1 / 2 & 2 \\ 1 / 2 & 1 / 2 & 1 & 3 & 1 / 2 & 1 / 2 & 1 / 3 & 1 / 2 \\ 1 / 4 & 1 / 4 & 1 / 3 & 1 & 1 / 3 & 1 / 3 & 1 / 4 & 1 / 4 \\ 1 / 2 & 1 / 2 & 2 & 3 & 1 & 2 & 1 / 3 & 1 / 2 \\ 1 / 2 & 1 / 2 & 2 & 3 & 1 / 2 & 1 & 1 / 3 & 1 / 2 \\ 2 & 2 & 3 & 4 & 3 & 3 & 1 & 2 \\ 1 / 2 & 1 / 2 & 2 & 4 & 2 & 2 & 1 / 2 & 1\end{array}\right|$

The weight judgment matrix $B_{2}-C$ of the second-level index of technicality evaluation:

$$
B_{2}-C=\left|\begin{array}{ccccc}
1 & 2 & 2 & 3 & 2 \\
1 / 2 & 1 & 1 / 2 & 2 & 1 / 2 \\
1 / 2 & 2 & 1 & 2 & 1 / 2 \\
1 / 3 & 1 / 2 & 1 / 2 & 1 & 1 / 3 \\
1 / 2 & 2 & 2 & 3 & 1
\end{array}\right|
$$

The weight judgment matrix $B_{3}-C$ of the second-level index of sociality evaluation:

$$
B_{3}-C=\left|\begin{array}{cccc}
1 & 2 & 1 / 2 & 2 \\
1 / 2 & 1 & 1 / 2 & 2 \\
2 & 2 & 1 & 2 \\
1 / 2 & 1 / 2 & 1 / 2 & 1
\end{array}\right|
$$

The weight judgment matrix $B_{4}-C$ of the second-level index of environmentality evaluation: 


$$
B_{4}-C=\left|\begin{array}{ccc}
1 & 1 & 3 \\
1 & 1 & 3 \\
1 / 3 & 1 / 3 & 1
\end{array}\right|
$$

The weight judgment matrix $B_{5}-C$ of the second-level index of security evaluation:

$$
B_{5}-C=\left|\begin{array}{cccc}
1 & 2 & 3 & 2 \\
1 / 2 & 1 & 2 & 2 \\
1 / 3 & 1 / 2 & 1 & 1 / 2 \\
1 / 2 & 1 / 2 & 2 & 1
\end{array}\right|
$$

And then used the MATLAB to calculate the weights of first-level evaluation indexes and second-level evaluation index respectively, the results are as follow:

$W^{(1)}=(0.405,0.177,0.065,0.091,0.262)$

$W_{1}^{(2)}=(0.182,0.153,0.070,0.036,0.099,0.083,0.249,0.128)$

$W_{2}^{(2)}=(0.341,0.136,0.181,0.087,0.257)$

$W_{3}^{(2)}=(0.276,0.195,0.391,0.138)$

$W_{4}^{(2)}=(0.429,0.429,0.142)$

$W_{5}^{(2)}=(0.418,0.271,0.120,0.191)$

The consistency test of the above six weight judgment matrixes is:

$$
C R=C I / R I=(0.0345,0.0338,0.0290,0.0454,0.0001,0.0266)
$$

The consistency test indexes of the above weight judgment matrixes are less than 0.1. Therefore, the consistency tests of the six judgment matrixes could be adopted, and the calculation result of evaluation indexes weight is scientific and reliable.

\subsection{The comprehensive evaluation model}

According to the calculation result of evaluation indexes weight, the comprehensive evaluation model of the energy trusteeship project of the regional distribution network could be obtained:

$$
A=W^{(1)} \bullet B=(0.405,0.177,0.065,0.091,0.262) \bullet\left(B_{1}, B_{2}, B_{3}, B_{4}, B_{5}\right)^{T}
$$

Namely,

$$
\begin{aligned}
& \text { Comprehensive Evaluation Model }(A)= \\
& 0.405 \times \text { Economy }\left(B_{1}\right)+0.177 \times \text { Technicality }\left(B_{2}\right) \\
& +0.065 \times \text { Sociality }\left(B_{3}\right)+0.091 \times \text { Environmentality }\left(B_{4}\right) \\
& +0.262 \times \operatorname{Security}\left(B_{5}\right)
\end{aligned}
$$

Where,

$$
\begin{aligned}
& \text { Economy }\left(B_{1}\right)=W_{1}^{(2)} \bullet C_{1}^{T} \\
& =0.182 \times I F C \_C_{11}+0.153 \times E T C \_C_{12} \\
& +0.070 \times O M C_{-} C_{13}+0.036 \times E A C \_C_{14} \\
& +0.099 \times I P P \_C_{15}+0.083 \times N P V \_C_{16} \\
& +0.249 \times T R R \_C_{17}+0.128 \times I R R \_C_{18}
\end{aligned}
$$

$$
\begin{aligned}
& \text { Technicality }\left(B_{2}\right)=W_{2}^{(2)} \bullet C_{2}^{T} \\
& =0.340 \times T T P \_C_{21}+0.136 \times T M \_C_{22} \\
& +0.180 \times T A p \_C_{23}+0.087 \times T A d \_C_{24}+0.257 \times T R \_C_{25} \\
& \text { Sociality }\left(B_{3}\right)=W_{3}^{(2)} \bullet C_{3}^{T} \\
& =0.276 \times P S I \_C_{31}+0.195 \times T R I \_C_{32} \\
& +0.391 \times P S \_C_{33}+0.138 \times R E G_{-} C_{34} \\
& \text { Environmentality }\left(B_{4}\right)=W_{4}^{(2)} \bullet C_{4}^{T} \\
& =0.429 \times L R R \_C_{41}+0.429 \times A E S_{-} C_{42} \\
& +0.142 \times C R A \_C_{43} \\
& \text { Security }\left(B B_{5}\right)=W_{5}^{(2)} \bullet C_{5}^{T} \\
& =0.418 \times P S R \_C_{51}+0.271 \times V Q R \_C_{52} \\
& +0.120 \times F Q R \_C_{53}+0.191 \times L S \_C_{54}
\end{aligned}
$$

\section{Conclusions}

The energy trusteeship is an effective mode to promote the energy conservation and emission reduction of the regional distribution network, but the lack of scientific decision-making basis has negative effect on the application of the energy trusteeship in the energy conservation and loss reduction management project of the regional distribution network. The construction of comprehensive evaluation mode could project a good toot to evaluate the feasibility of the energy trusteeship project of regional distribution system and provide the project decision-making for energysaving service companies and power enterprises.

The paper designed the comprehensive evaluation index system of the energy trusteeship project of the regional distribution network, and then calculated the weight after collecting evaluation data of the relative importance of evaluation index on basis of Analytic Hierarchy Process. Finally, the comprehensive evaluation mode of the energy trusteeship of regional distribution system was constructed. The paper did some helpful exploration and research on the development of EPC, especially the energy trusteeship mode, in the field of the energy conservation and emissions reduction of the regional distribution network.

\section{Acknowledgements}

This paper is supported by "Science and technology project funding by State Grid Corporation of China (Grant No. 27KJ010501C1016320140000)".

\section{References}

[1] Principi P, Roberto F, Carbonari A, et al. Evaluation of energy conservation opportunities through Energy Performance Contracting: A case study in Italy. Energy \& Buildings, 2016, 128, pp. 886-899.

[2] Bertoldi P, Rezessy S, Vine E. Energy service companies in European countries: Current status and a strategy to foster their development Energy Policy, 2006, 34, (14), pp. 1818-1832.

[3] Painuly J P, Park H, Lee M K, et al. Promoting energy efficiency financing and ESCOs in developing countries: mechanisms and barriers. Journal of Cleaner Production, 2003, 11, (6), pp. 659-665.

[4] Lee S E, Rajagopalan P. Building energy efficiency labelling programme in Singapore. Energy Policy, 2008, 36, (10), pp. 3982-3992.

[5] CHEN Hui. Global energy service industry development analysis and its enlightenment. Power Demand Side Management, 2009, 11, (1), pp. 73-76.

[6] XU Wenxiu, HUANG Ke, ZHANG Libing, et al. Low-Carbon Optimization and Economic Benefit for Distribution Network Based on Energy Management Contract. Electric Power Construction, 2015, 36, (6), pp. 134138.

[7] Huang Na, Lu Bingshan. Research on energy saving service operation mode based on the energy trusteeship of the power grid enterprises. Guizhou Electric Power Technology, 2014, (3), pp. 26-28. 
[8] WU Yu-lin, WU Wen-ke, ZHANG Yong, et al. Implementation of energy performance contracting in power grid corporations. Journal of North China Electric Power University (Natural Science Edition), 2011, 38, (5), pp. 59-64.

[9] LEI Ming. Practical application of enemy management contract in enemy saving service carried out by power grid enterprises. Power Demand Side Management, 2008, 10, (6), pp. 30-32.
[10]Han Xiaohui, Du Songhuai, Su Juan, et al. Energy efficiency evaluation method of rural low-voltage distribution network based on combination weight method. Transactions of the Chinese Society of Agricultural Engineering, 2014, 16, pp. 195-202.

[11]LI Tao, YAO Kun, LIAO Yuan, et al. Evaluation Method for Energy Conservation of Line Loss of $10 \mathrm{kV}$ Power Distribution Network Based on Interval Method. Guangdong Electric Power, 2015, (5), pp. 95-98. 